\title{
Review on Face, Ear and Signature for Human Identification
}

\author{
Suvarnsing G. Bhable \\ Research Student \\ Department of Computer \\ Science \& Information \\ Technology \\ Dr. Babasaheb Ambedkar \\ Marathwada University, \\ Aurangabad
}

\author{
Sumegh Tharewal \\ Research scholar \\ Department of Computer \\ Science \& Information \\ Technology \\ Dr. Babasaheb Ambedkar \\ Marathwada University, \\ Aurangabad
}

\author{
Hanumant Gite \\ Research scholar \\ Department of Computer \\ Science \& Information \\ Technology \\ Dr. Babasaheb Ambedkar \\ Marathwada University, \\ Aurangabad
}

\author{
Siddharth Dabhade \\ Research scholar \\ Department of Computer Science \& Information \\ Technology \\ Dr. Babasaheb Ambedkar \\ Marathwada University, \\ Aurangabad
}

\author{
K. V. Kale \\ Professor \\ Department of Computer Science \& Information \\ Technology \\ Dr. Babasaheb Ambedkar \\ Marathwada University, \\ Aurangabad
}

\begin{abstract}
Biometrics is a rising technology, which has been extensively used in robotics areas financial services, forensics, secured access, prison security, medical, telecommunication, ecommerce, government, traffic, health care the security issue are more essential. Biometric-based personal identification is high applicability in an extensive range of security application but Multimodal biometrics is the way to reduce time density and give better recognition rate. The concert rate of unimodal biometric is frequently reduced due to the user mode and physiological defects. We have referred papers related to face, ear and signature. In this paper, we discuss different methods of Face, Ear and signature for recognition and identification.
\end{abstract}

\section{Keywords}

Face, Ear, Signature, LDA, PCA, Borda count method, Logistic regression method and Rank level Fusion

\section{INTRODUCTION}

Biometric identification is the technology used for recognize a human identity based upon their physiological or behavioral characteristic and extracts their pattern information then extracted pattern information must be measured quantitatively for identification of a person in a simple and automated way [1]. The invariant, measurable, acceptable, permanence properties of biometric traits makes it extremely appropriate to be integrated in human identification. The biometric trait is extremely conventional by the user, when it is easily read by the system. The physical traits depend upon the morphological uniqueness of subject, while the behavioral traits quantify unique actions performed by the subjects. Physiological biometric traits are face, fingerprint, hand-geometry, palm print, iris, retina, etc., and behavioral biometric traits are signature, voice, gait and keystroke dynamics.

Multibiometrics is a relatively new approach to overcome those problems by consolidating evidences presented by multiple biometric sources. What are the Evidences in a multibiometrics system several levels - rank level, feature level, sensor level, match score level, and decision level [24]. Rank level fusion is studied by few researchers and able to be effectively used to consolidate more than one unimodal biometric system's ranked output. Review of Principal Component

Analysis and Fisher's Liner Discriminant in face, ear and signature. For achieving higher recognition rate they were use rank level fusion.

\section{LITERATURE REVIEW}

Gaussian Mixture Model- based feature extraction technique follow by accepted subspace methods for accurate multimodal biometric system. There are four dissimilar feature extraction techniques that are PCA Mixture Model, ICA I MM (Independent Component Analysis I Mixture Model), SVD MM (Singular Value Decomposition Mixture Model), and ICA II MM (Independent Component Analysis II Mixture Model) to intend a multimodal biometric system at feature level. The designed methods start in on with modeling the multimodal biometrics data with Gaussian Mixture Model followed by a subspace method like SVD, ICAII, ICAI and PCA. Broad-spectrum experiments are carried out to observe the authentication show of the proposed method at characteristic and match score level the results reveal the efficiency of the proposed methods in conniving a robust multimodal biometric system for perfect person authentication.

Gaussian Mixture Model-based approaches provide more than one transformation matrix that allows for better representation of the multimodal biometric features. Gaussian Mixture Model is more robust to noise as compared to than conventional methods, Multimodal biometrics often perform better than unimodal biometrics. When combining them, however, the best of both does not yield overall best. Success of multimodal depends on "redundancy" of modalities chosen. At feature level fusion, the best result is noted on fusing the complementary algorithms on complementary modalities like face and palmprint [2].

Multimodal biometric recognition approach based on the fea- 
tures of palmprint and face. Database - ORL database contains 400 facial images: ten images of one user. The size of each image is $92 * 112$ with 256 gray levels. Two feature extraction methods are in employment, first one is base on the SP (statistics properties) of the biometric images and the other is the traditional 2D principal component analysis (2DPCA). The minimum distance rule (MDR) is adopt for fusion of the match score level and compare the outcome of the multimodality recognition with the results of the unimodal palmprint and face recognition. The results shows the performance of multimodality outperforms the unimodal recognition and the correctness can reach $100 \%$ based on ORL and PolyU database using the fusion rule at the match score level [3].

Multimodal biometric recognition system fingerprint, palmprint and face base on score level fusion (SLF). The feature vectors are extracted separately from the pre-processed images of fingerprint, palmprint and face (Principal Component Analysis). That feature vectors of query images are then compare independently with the staffing templates used and store through database training for each biometric trait. Individual match scores generated after matching of uncertainty image through the database images are passed to the fusion element. Fusion of normalize scores by weighted sum rule. Weights connected with each biometric trait for a definite user indicate the importance of equivalent biometric characteristic obsessed by the consumer. Individual normalized scores all along with weights are finally combined into an overall score via sum rule, which be passing to the decision element that declare the person an imposter genuine or imposter. The uniqueness established by that system is more consistent than the characteristics established by character biometric systems. Integrate multiple biometric traits improves identification performance and reduces fake access [4].

Multimodal 2D+3D faces identification, connecting 198 people in the gallery and moreover 198 or 670 time-lapse explore images. PCA-base method is used discretely for each modality and match scores in the take apart face spaces are combined for multimodal identification.

Major conclusions:

- $\quad$ Considered individually $2 \mathrm{D}+3 \mathrm{D}$ recognition was similar

- $\quad$ combine 2D \& 3D results using a simple weighting scheme outperforms also 2D or 3D only

- $\quad$ combine outcome from two or more 2D images using a similar weighting scheme also outperforms a particular 2D image,

- $\quad$ Combine $2 \mathrm{D}+3 \mathrm{D}$ outperforms the multiple image 2D result [5].

Talk about how the image excellence of face, fingerprint and iris use in the multimodal biometric systems will concern the overall detection accuracy and the need of enrollment for the secondary human corroboration. Multimodal biometric systems using face, fingerprint and iris recognition using score level fusion, levels of fusion that are potential and the integration strategy can be adopt to fuse information and get better overall system accurateness [6][26].

Novel fusion method called non-stationary feature fusion somewhere a latest construction of interleaved matrix is constructed by local features extracted (LCE) from two modalities that is palmprint and face images. Discrete Cosine Transform algorithm is used to make a combined feature vector by extracting independent feature vectors from every spatial image. These fused feature vectors contain nonlinear information that is used to train a Gaussian Mixture Model based statistical model. The models provide correct assessment of the class conditional probability density function of the fused feature vector. Method produce recognition rates as high as $97 \%$ and 99.7\% when test on standard databases- FERET-PolyU and ORL-PolyU correspondingly. These rates are achieved using $23 \%$ low down frequency DCT coefficients. Feature level fusion methods including methods based on matching and decision level fusion.

The results suggest that fusing local features based on block based DCT give high discriminating power when each block has a 4 pixel overlap and the number of DCT coefficients is 15 . The performance of the proposed method is tested using three benchmark datasets (FERET, PolyU and ORL) to create a multimodal REFET-PolyU dataset that achieve 97\% accurateness and a multimodal ORL-PolyU dataset that achieves $99.7 \%$ accuracy. A comparison with to several existing methods which also use fusion at the feature level and use the same datasets [7].

The effectiveness of selecting the inequitable set of KCMs as the local and global face facial appearance as different to customary facial appearance obtained from heuristic option of fixed-order moment or outcrop of the moment for recognizing characteristics. The assortment of significantly sparse 2D KCM-base facial appearance according to the planned approach results in highly inventive face identification method as compare to the other methods with the purpose of use orthogonal moments such as the 2DZernike, 2DTchebiche for 2DGaussian-Hermite. Experiment on demanding databases (viz., CK-AUC and FRGC) and comparison with the good established projection, texture, and instant based methods specify superior identification performance in terms of mean rightness and robustness of the future holistic-or hybrid-type discriminative KCM-base method, particularly when sample sizes are little and the intra collection faces have significant variations due to expressions [8].

A multi-modal biometric system combines Ear and face (2D+3D) features at different levels that use Microsoft Kinect. Beginning with the review of presented algorithms, apply to Ear and face $(2 D+3 D)$ data, they were focused on fast discrete curvelet transformation techniques for face (2D+3D) identification and dynamic contour algorithm technique for ear recognition. The result optimal fusion level and avoid redundancy in the extracted features. In that paper lighting conditions, create variations, aging and can completely reinstate the current recognition systems economically and give a better security. Total of 250 subjects participates in data acquisition sessions through kinect. The results are obtained separately each biometric and fusion at metric level for good accuracy. Multimodal algorithm performed enhanced by achieving $97 \%$ and $95 \%$ recognition rates with 0.01 false acceptance rates (FAR) which are greater than either ear recognition or $2 \mathrm{D}$ face or $3 \mathrm{D}$ face algorithm alone in a numerical and significant manner.

Face recognition curvelet transform is used to extract the feature vector co-efficient and ear active contour is used to extract the features. The extracted features were then used to calculate the similarity between images. That resulted in match score for each modality. Match scores obtain from the two modalities (face and ear) were fused at the match score level using the weighted sum method [9].

Multimodal biometric recognition system for ear and profile face by using novel non-intrusive technique. Only the face profile observation images are captured for detection. Then after ear classifier and profile face classifier based on FSLDA (Full Space Linear Discriminant Analysis) are set up. In the 
stage of decision fusion of ear and profile face is carried out using the combination methods of Product, Sum and Median rules according to the Bayesian theory and a modified Vote rule for two classifiers is obtainable. The results of experiment show that the recognition rate (RR) is higher than that of the recognition adopting the single feature, and that the recognition range is larger than that of both unimodality [10]

Multimodal biometric database (MBD) considered and acquire within European BioSecure set of connections of distinction exists. It was comprised of 600 individuals obtain simultaneously in 3 scenarios:

\section{- Internet (Over)}

- Office location with desktop

- Indoor/outdoor location with mobile hardware.

In that above three scenarios contain the common part of audio/video database. Fingerprint and Signature data acquired from desktop and mobile hardware. In additionally, iris and hand database were acquired in the second scenario using desktop PC. Possession has been conducted by Eleven European institutions. Skin texture of the BioSecure Multimodal Database (BMDB) are: acquisition session, several sensors in convinced modalities, impartial age and gender classification, multimodal pragmatic scenarios with simple and quick tasks per modality, cross-European diversity, accessibility of demographic data, and compatibility with other multimodal databases. The novel acquisition conditions of the BMDB allow us to carry out new challenging research and evaluation of either monomodal or multimodal biometric systems, as in the current BioSecure Multimodal Evaluation campaign. A description of this campaign including baseline results of individual modalities from the new database is also given. The database is expected to be available for research purposes through the BioSecure Association during 2009.

The recently acquire BioSecure Multimodal Database was present together with a brief description of previous work in the domain of multimodal biometric database acquisition. This database is the result of an important collaborative effort of 11 European partners of the BioSecure NoE. It includes new challenging acquisition conditions and features not present in existing databases. It is comprised of three different data sets with more than 600 common individuals captured in two sessions: 1) one data set acquired over the Internet, 2) another one acquired in an office environment with a desktop PC, and 3) the last one acquired with mobile devices in indoor/outdoor environments. The three data sets include a common part of audio and video data which comprise still images of frontal face and talking face videos acquired with a Webcam. Additionally, the second data set includes still face (with a digital camera), signature, fingerprint (with two different sensors), and hand and iris data, and the third one also includes signature and fingerprint data. Also worth noting, the BioSecure Multimodal Database shares a number of individuals with other multimodal databases acquired across several years, allowing studies of long-term variability [11].

Face identification is fast but not exceptionally reliable; about fingerprint verification is reliable but inefficient in database retrieval. The system overcomes the limitations of face recognition systems as well as fingerprint verification systems. The ecision fusion scheme enables performance improvement by integrating multiple cues with different confidence measures. The limitations of both face-recognition systems and fingerprint- verification systems. The integrated system operates in the identification mode. The decision-fusion scheme formu- lated in the system enables performance improvement by integrating multiple cues with different confidence measures. It meets the response time as well as the accuracy requirements [12].

Non-negative dictionary based sparse representation and classification scheme for ear recognition. The non-negative dictionary includes the Gabor features dictionary extracted from the ear images, and non-negative occlusion dictionary learned from the identity occlusion dictionary. A test sample with occlusion can be sparsely represented over the Gabor feature dictionary and the occlusion dictionary. The sparse coding coefficients are noted with non-negativity and much more sparsity, and the non-negative dictionary has shown increasing discrimination ability. Experimental results on the USTB ear database show that method performs better than existing ear recognition methods under partial occlusion based on SRC. learn a nonnegative Gabor feature based occlusion dictionary instead of using an identity matrix as occlusion dictionary. The sparse coding coefficients with these two dictionaries are all positive. The learned dictionary not only has lower dimensions, but also enhances the discriminative ability of the atoms, which in turn increases the sparseness of the sparse code vector. Experimental results have shown that the sparse coding coefficients of ND_ NSRC are much sparser than the original SRC or the Gabor occlusion dictionary based SRC. Extensive experimental results on the USTB datasets with various percentage of occlusion at random locations have shown that the proposed ND_NSRC is robust to image occlusions [13].

Use the snake model to identify the ear, and applied median filter for remove noise, also they improved the images to binary format. After that they used canny edge and made some improvement on the image, largest boundary is calculated and distance matrix is created then we extracted the image features. Finally, the extracted features were classified by using nearest neighbor with absolute error distance. This method is invariant to scaling, translation and rotation. The experimental results showed that the proposed approach gives better results and obtained over all accuracy almost 98\% [14].

New method of the combined use of signatures and utterances of pronounced names to identify or authenticate persons. Unlike typical signature verification methods, the dynamic features of signatures are captured as sound in this paper. The multimodal approach shows increased reliability, providing a relatively simple and potentially useful method for person identification and authentication.

The use of signature and pronounced names are generally acceptable to most users and for many applications. Both signatures and voices can be acquired by a microphone attached to the end of a rigid-nib pen. Bluetooth or similar transmitter can be built into the pen to make it wireless. The total sound approach to multimodal biometric information acquisition was reduces the complexity, making the information easier to transmit via diverse channels, e.g. computer/internet or traditional the public switched telephone network (PSTN). Given the high recognition rate, the potentially useful person identification and authentication system for many applications. It is also worth noting that although the method shows great potential in general and the pattern recognition algorithms adopted in this paper give promising results, the algorithms and training regimes are far from optimal. Many aspects can be improved and need further work. Alternative schemes and algorithms may include using statistical or probabilistic pattern matching and distance criteria for all pattern recognitions involved. This can potentially enable more sophisticated final decisionmaking schemes [16]. 
The biometrics verification techniques combining with digital signature for multimodal biometrics payment system are introduced. Considering the high universality, distinctiveness, easy collectability of fingerprint and face, a multimodal biometrics verification system with fingerprint and face as inputs is designed, and the hybrid fingerprint features and infrared (IR) face features for matching is to overcome the shortcomings of the traditional methods and dependent the integrity of the registered multimodal biometrics data and then nine authentication models for authenticating an open network to ensure the integrity of these data are analyzed respectively. At last, a digital signature procedure with the Public Key Infrastructure (PKI) to illustrate a multimodal biometrics payment system with safe model is proposed. Adopt the approach of fusion at the feature extraction level [17]

Multibiometrics systems seek to alleviate some of these drawbacks by providing multiple evidences of the same identity. These systems help achieve an increase in performance that may not be possible using a single biometric indicator. Further, multibiometrics systems provide anti-spoofing measures by making it difficult for an intruder to spoof multiple biometric traits simultaneously. However, an effective fusion scheme is necessary to combine the information presented by multiple domain experts. The problem of information fusion in biometric verification systems by combining information at the matching scores level. Experimental results on combining three biometric modalities (face, fingerprint and hand geometry) are presented. The benefits of multibiometrics may become even more evident in the case of a larger database of users. They were, therefore, in the process of collecting data corresponding to four biometric indicators fingerprint, face, and voice and hand geometry from a larger user set (100) [18].

Automated ear segmentation using morphological operators and Fourier descriptors has been quite effective in the robust segmentation of the curved region of interest. Another key effort in this paper has been to investigate new feature extraction approaches for the $2 \mathrm{D}$ ear images. We have exploited the local orientation features using even Gabor filters and achieved superior performance with prior approaches (using eigen ear, force field transform, shape features). However the best performance, i.e., rank-one recognition accuracy of $96.27 \%$ and $95.93 \%$, respectively, on the database of 125 and 221 subjects, was observed from the feature extraction approach using a pair of logGabor filters and the FPIR vs. FNIR performance have also suggested that the log-Gabor based feature extraction approach outperforms other feature extraction approach considered in this work. One of the key observations of our work is related to the effectiveness of shape features in a completely automated system. Despite our best efforts to achieve the robust localization of curved ear shape and its representation, the achieved performance was poor. Our observations have suggested that the discriminibility of such shape features is quite limited, especially in the presence of large number of subjects as in our work. The ear database acquired in this work from 125 subjects (also 221 subjects), along with segmented images is made publicly available to the researchers [19].

Multi-section vector quantization approach for on-line signature recognition. They have used the MCYT database, which consists of 330 users and 25 skilled forgeries per person performed by 5 different impostors. In that database is larger than those typically used in the literature. Nevertheless, they also provide results from the SVC database. They proposed system out performs the winner of SVC with a reduced computational requirement, which is around 47 times lower than DTW. In addition, is more privacy-friendly as it is not possible to recover the original signature using the codebooks. Experimental results with MCYT provide a $99.76 \%$ identification rate and $2.46 \%$ EER (skilled forgeries and individual threshold). Experimental results with SVC are 100\% of identification rate and $0 \%$ (individual threshold) and $0.31 \%$ (general threshold) when using a two-section VQ approach [19].

Artificial Immune Systems (AIS) seem suitable to automatically detect forgeries in signature verification systems. Offline signature verification is based on the Artificial Immune Recognition System (AIRS). For feature generation, two different descriptors are proposed to generate signature traits. The first is the Gradient Local Binary Patterns that estimates gradient features based on the LBP neighborhood. The second descriptor is the Longest Run Feature, which describes the signature topology by considering longest suites of text pixels. Performance evaluation is carried out on CEDAR and GPDS 100 datasets. The results obtained showed that the proposed system has promising performance and often comfortably out performs the state of the art [20].

An automatic signature verification system has been proposed. This work focuses on both online and offline features of handwritten signatures and aims at combining their results to verify the signature. Signatures are collected for both online and offline. Online data collected is the signing process captured using a webcam and offline data collected are the scanned signatures. Initially both data undergoes appropriate preprocessing steps. Then feature extraction is done where features based on pen tip tracking are used in case of online and gradient and projection based features are used in case of offline method. Later the online and offline method verifies the signature separately and finally their results are combined and the signature is verified using SVM. Paper also compares the results of online, offline and combined approach.

Different unimodal face recognition techniques namely Eigenface, Fisherface, LBP and A-LBP and the possible fusion of these techniques. In particular, the performance of fused techniques such as Eigenfaces and LBP, Fisherfaces and LBP, Eigenfaces and A-LBP, and Fisherfaces and A-LBP is evaluated on publicly available face databases using Bray Curtis dissimilarity metric. The recognition results obtained by the fused technique are found optimum in comparison to their unimodal technique.

ICP matching of the 3D data, achieving 97.5\% on a 404-person dataset. ICP-based matching not only achieves the best performance, but also shows good scalability with size of dataset. The data set used represents over 400 persons, each with images acquired on two different dates. In order to test the robustness and variability of ear biometrics, ear symmetry is also investigated. In our experiments around $90 \%$ of people's right ear and left ear are symmetric. Several topics for additional work seem important and promising. One is to consider methods of improving the computation time required by ICP matching. Another is to further investigate the scalability of $3 \mathrm{D}$ ear recognition performance with increased data set size. A third topic is to investigate possible performance improvement by combining $2 \mathrm{D}$ and $3 \mathrm{D}$ recognition for a multi-modal result [23].

An implementation of person identification fusing face, ear and iris biometric modalities used PCA based neural network classifier for feature extraction from the face and ear images and hamming distance for calculating iris templates. These features fused and used for identification. Better result was obtained if the modalities were combined. Identification was made using Eigen faces, Eigen ears, Template of iris and their features tested over the self created image database [24]. 
Multimodal biometric system for Face, Ear and Signature based on PCA and Fisher's Linear Discriminant methods that is use face, ear and signature for identification and rank level fusion for consolidate the outcome obtained from these monomodal matchers. The ranks of entity matchers are combining use of Borda count method and logistic regression method. The results indicate that fusing individual modalities get better the overall performance of the biometric system [25].

Table 1: A Few Multibiometrics Systems Discussed In Literature

\begin{tabular}{|c|c|c|c|c|c|c|c|c|}
\hline & & & & & & & & \\
\hline $\begin{array}{l}\text { Sr.N } \\
\text { o. }\end{array}$ & $\begin{array}{l}\text { Author \& } \\
\text { Year }\end{array}$ & $\begin{array}{l}\text { Biome- } \\
\text { trics } \\
\text { Traits }\end{array}$ & $\begin{array}{l}\text { Data- } \\
\text { set }\end{array}$ & Database & Techniques & $\begin{array}{l}\text { Level } \\
\text { of } \\
\text { Fu- } \\
\text { sion }\end{array}$ & $\begin{array}{l}\text { Re- } \\
\text { sult } \\
\text { in } \\
\%\end{array}$ & Future Work \\
\hline 1 & $\begin{array}{l}\text { R. Ragha- } \\
\text { vendra } \\
2012\end{array}$ & $\begin{array}{l}\text { Palmprit, } \\
\text { Face } \\
\text {,Speech }\end{array}$ & 150 & $\begin{array}{l}\text { FRGC } \\
\text { Face } \\
\text { polyU- } \\
\text { Palmprint } \\
\text { TIMIT- } \\
\text { Speech }\end{array}$ & $\begin{array}{l}\text { Mixture Model } \\
\text { (PCA MM), Singu- } \\
\text { lar Value Decom- } \\
\text { position } \\
\text { Mixture Model } \\
\text { (SVD MM), Inde- } \\
\text { pendent Compo- } \\
\text { nent Analysis } \\
\text { I Mixture Model } \\
\text { (ICA I MM), and } \\
\text { Independent Com- } \\
\text { ponent } \\
\text { Analysis II Mixture } \\
\text { Model (ICA II } \\
\text { MM) }\end{array}$ & $\begin{array}{l}\text { fea- } \\
\text { ture } \\
\text { and } \\
\text { matc } \\
\mathrm{h} \\
\text { score } \\
\text { level }\end{array}$ & 97 & $\begin{array}{l}\text { Improved success in } \\
\text { multimodal cases is } \\
\text { obtained by having } \\
\text { structurally diverse } \\
\text { modality than just "re- } \\
\text { dundant" } \\
\text { Modality. }\end{array}$ \\
\hline 2 & $\begin{array}{l}\text { Cheng Lu } \\
\text { \& Jisong } \\
\text { Wang, } \\
\text { Miao Qi } \\
2009\end{array}$ & $\begin{array}{l}\text { Face } \\
\text {,Palmprin } \\
\mathrm{t}\end{array}$ & $\begin{array}{l}400 \\
\text { face } \\
400 \\
\text { Palmp } \\
\text { rint }\end{array}$ & $\begin{array}{l}\begin{array}{l}\text { ORL- } \\
\text { face }\end{array} \\
\text { PolyU- } \\
\text { Palmprint }\end{array}$ & $\begin{array}{l}\text { statistics properties } \\
(\mathrm{SP}) \& \text { two- } \\
\text { dimensional } \\
\text { principal compo- } \\
\text { nent analysis } \\
\text { (2DPCA) }\end{array}$ & $\begin{array}{l}\text { score } \\
\text { level }\end{array}$ & $\begin{array}{l}99 . \\
5\end{array}$ & $\begin{array}{l}\text { Accuracy can reach } \\
100 \% \text {. }\end{array}$ \\
\hline 3 & $\begin{array}{l}\text { Sheetal } \\
\text { Chaud- } \\
\text { hary, Ra- } \\
\text { jender } \\
\text { Nath } 2009\end{array}$ & $\begin{array}{l}\text { Palmprint } \\
\text {, Finger- } \\
\text { print and } \\
\text { Face }\end{array}$ & NA & $\begin{array}{l}\text { individu- } \\
\text { al }\end{array}$ & $\begin{array}{l}\text { Sum Rule, } \\
\text { Euclidean distance, } \\
\text { PCA }\end{array}$ & $\begin{array}{l}\text { score } \\
\text { level }\end{array}$ & NA & $\begin{array}{l}\text { integrating liveness } \\
\text { detection with multi- } \\
\text { modal } \\
\text { biometric systems and } \\
\text { minimizing the com- } \\
\text { plexity of the system. }\end{array}$ \\
\hline 4 & $\begin{array}{l}\text { Kyong I. } \\
\text { Chang, } \\
\text { Kevin W. } \\
\text { Bowyer, } \\
\text { and Pa- } \\
\text { trick J. } \\
\text { Flynn } \\
2005\end{array}$ & $\begin{array}{l}2 \mathrm{D}+3 \mathrm{D} \\
\text { Face }\end{array}$ & 198 & NA & PCA & $\begin{array}{l}\text { matc } \\
\mathrm{h} \\
\text { score }\end{array}$ & $\begin{array}{l}92 . \\
4\end{array}$ & $\begin{array}{l}\text { 3D face recognition is } \\
\text { the development of } \\
\text { better } \\
\text { 3D sensing technology. }\end{array}$ \\
\hline 5 & $\begin{array}{l}\text { Teddy Ko } \\
2005\end{array}$ & $\begin{array}{l}\text { Finger- } \\
\text { print, } \\
\text { Face and } \\
\text { Iris }\end{array}$ & NA & NA & PCA & $\begin{array}{l}\text { score } \\
\text { level }\end{array}$ & NA & NA \\
\hline 6 & $\begin{array}{l}\text { Muham- } \\
\text { mad Im- } \\
\text { ran Ah- } \\
\text { mad, Wai } \\
\text { Lok Woo, } \\
\text { Satnam } \\
\text { Dlay }\end{array}$ & $\begin{array}{l}\text { face and } \\
\text { palmprint }\end{array}$ & 800 & $\begin{array}{l}\text { ORL-face } \\
\text { PolyU } \\
\text { and } \\
\text { FERET- } \\
\text { PolyU- } \\
\text { palmprint }\end{array}$ & $\begin{array}{l}\text { A block based } \\
\text { Discrete Cosine } \\
\text { Transform (DCT) } \\
\& \text { Gaussian Mix- } \\
\text { ture Models } \\
\text { (GMM) based sta- } \\
\text { tistical model }\end{array}$ & $\begin{array}{l}\text { Fea- } \\
\text { ture } \\
\& \\
\text { deci- } \\
\text { sion } \\
\text { level } \\
\text { fu- } \\
\text { sion }\end{array}$ & $\begin{array}{l}99 . \\
7\end{array}$ & NA \\
\hline 7 & $\begin{array}{l}\text { S.M. } \\
\text { Mahbubur } \\
\text { Rahman , } \\
\text { Tamanna }\end{array}$ & Face & 466 & $\begin{array}{l}\text { FRGC } \\
\text { V2.0 and } \\
\text { CK-AUC }\end{array}$ & $\begin{array}{l}\text { Two-Dimensional } \\
\text { Krawtchouk mo- } \\
\text { ments (2D KCMs), } \\
\text { PCA, LDA \& 2D- }\end{array}$ & NA & $\begin{array}{l}98 . \\
70\end{array}$ & NA \\
\hline
\end{tabular}




\begin{tabular}{|c|c|c|c|c|c|c|c|c|}
\hline & $\begin{array}{l}\text { Howlader, } \\
\text { et al. }\end{array}$ & & & & PCA & & & \\
\hline 8 & $\begin{array}{l}\text { M.Pujitha } \\
\text { Raj, Man- } \\
\text { jusha.R, } \\
\text { B.Achyut } \\
\text { Sarma, } \\
\text { S.Vaishna } \\
\text { vi }\end{array}$ & $\begin{array}{l}\text { Ear and } \\
\text { face } \\
(2 D+3 D)\end{array}$ & 250 & \begin{tabular}{ll}
\multicolumn{2}{c}{ captured } \\
$2 \mathrm{D}$ & im- \\
ages & us- \\
ing & Ki- \\
nect &
\end{tabular} & Eigen Faces & $\begin{array}{l}\text { Matc } \\
\mathrm{h} \\
\text { score } \\
\text { Fea- } \\
\text { ture } \\
\text { fu- } \\
\text { sion } \\
\text { level }\end{array}$ & 97 & $\begin{array}{l}\text { Robustness to both } \\
\text { illumination and pose } \\
\text { variations. }\end{array}$ \\
\hline a. 9 & $\begin{array}{l}\text { Xiaona } \\
\text { Xu, Zhi- } \\
\text { chun Mu } \\
2007\end{array}$ & $\begin{array}{l}\text { Ear and } \\
\text { Profile } \\
\text { face }\end{array}$ & 294 & $\begin{array}{l}\text { Universi- } \\
\text { ty of } \\
\text { Science } \\
\text { and } \\
\text { Technol- } \\
\text { ogy Bei- } \\
\text { jing } \\
\text { USTB }\end{array}$ & $\begin{array}{l}\text { Full- } \\
\text { Space Linear Dis- } \\
\text { criminant Analysis } \\
\text { (FSLDA) \& Baye- } \\
\text { sian Combination } \\
\text { Method }\end{array}$ & $\begin{array}{l}\text { deci- } \\
\text { sion } \\
\text { fu- } \\
\text { sion }\end{array}$ & $\begin{array}{l}97 . \\
62\end{array}$ & $\begin{array}{l}\text { NA } \\
\text { effective approach of } \\
\text { non-intrusive biometric } \\
\text { recognition. }\end{array}$ \\
\hline 10 & $\begin{array}{l}\text { Javier } \\
\text { Ortega- } \\
\text { Garcia et } \\
\text { al., etc... } \\
2010\end{array}$ & $\begin{array}{l}\text { finger- } \\
\text { print, } \\
\text { Face, } \\
\text { speech, } \\
\text { and iris. }\end{array}$ & 2351 & $\begin{array}{l}\text { Individu- } \\
\text { al }\end{array}$ & PCA & NA & NA & NA \\
\hline 11 & $\begin{array}{l}\text { Lin Hong } \\
\text { and Anil } \\
\text { Jain } 1998\end{array}$ & $\begin{array}{l}\text { Faces and } \\
\text { Finger- } \\
\text { prints }\end{array}$ & $\begin{array}{l}1500 \\
- \\
\text { finger- } \\
\text { ger- } \\
\text { print } \\
1132- \\
\text { face }\end{array}$ & $\begin{array}{l}\text { MSU- } \\
\text { Finger- } \\
\text { print, } \\
\text { Olivetti } \\
\text { Research } \\
\text { Lab- Face }\end{array}$ & PCA & $\begin{array}{l}\text { Deci- } \\
\text { sion } \\
\text { fu- } \\
\text { sion }\end{array}$ & NA & NA \\
\hline 12 & $\begin{array}{l}\text { Li Yuan, } \\
\text { Wei Liu, } \\
\text { Yang Li } \\
2015\end{array}$ & Ear & NA & USTB , & $\begin{array}{ll}\text { NSRC } & \& \\
\text { ND_NSRC } & \end{array}$ & NA & $\begin{array}{l}99 . \\
87\end{array}$ & $\begin{array}{l}\text { ND_NSRC will robust } \\
\text { to image occlusions }\end{array}$ \\
\hline 13 & $\begin{array}{l}\text { Asmaa } \\
\text { Sabet } \\
\text { Anwar et } \\
\text { al, 2015 }\end{array}$ & Ear & 150 & $\begin{array}{l}\text { IIT Delhi } \\
\text { Ear }\end{array}$ & $\begin{array}{l}\text { Nearest Neighbor, } \\
\text { Euclidean distance, } \\
\text { Median filter }\end{array}$ & NA & 98 & $\begin{array}{l}\text { Drop-down hair on the } \\
\text { ear, which } \\
\text { Obscures part of them. }\end{array}$ \\
\hline 14 & $\begin{array}{l}\text { Francis F. } \\
\mathrm{Li} 2010\end{array}$ & $\begin{array}{l}\text { Signature } \\
\text { and Voice }\end{array}$ & 100 & NA & $\begin{array}{l}\text { ANN, PR } \\
\text { Mel-frequency } \\
\text { warped cepstral } \\
\text { coefficients } \\
\text { (MFCCs) }\end{array}$ & NA & 97 & NA \\
\hline 15 & $\begin{array}{l}\text { JuCheng } \\
\text { Yang } \\
2010\end{array}$ & $\begin{array}{l}\text { Signature } \\
\text { and Pay- } \\
\text { ment } \\
\text { System }\end{array}$ & NA & NA & $\begin{array}{l}\text { skin heat transfer } \\
\text { (SHT) model }\end{array}$ & $\begin{array}{l}\text { Score } \\
\& \\
\text { Dece- } \\
\text { ce- } \\
\text { sion } \\
\text { level }\end{array}$ & NA & $\begin{array}{l}\text { Improve the robustness } \\
\text { and } \\
\text { Accuracy of the system. }\end{array}$ \\
\hline 16 & $\begin{array}{l}\text { Arun } \\
\text { Ross, Anil } \\
\text { Jain } 2003\end{array}$ & $\begin{array}{l}\text { Face, } \\
\text { Finger- } \\
\text { print, } \\
\text { Hand } \\
\text { geometry }\end{array}$ & 250 & NA & $\begin{array}{l}\text { PCA, Sum rule, } \\
\text { Decision trees, } \\
\text { Linear discriminant } \\
\text { function }\end{array}$ & $\begin{array}{l}\text { Sum } \\
\text { rule }\end{array}$ & $\begin{array}{l}99 . \\
77\end{array}$ & $\begin{array}{l}\text { developing user } \\
\text { Specific weights for the } \\
\text { individual modalities. } \\
\text { Different } \\
\text { users tend to adopt } \\
\text { differently to individual } \\
\text { biometric indicators }\end{array}$ \\
\hline 17 & $\begin{array}{l}\text { Ajay Ku- } \\
\text { mar, } \\
\text { Chenye }\end{array}$ & Ear & 465 & NA & $\begin{array}{l}\text { log-Gabor based } \\
\text { feature extraction }\end{array}$ & NA & $\begin{array}{l}96 . \\
27\end{array}$ & $\begin{array}{l}\text { Improve the automated } \\
\text { ear segmentation capa- } \\
\text { bility in the indoor }\end{array}$ \\
\hline
\end{tabular}




\begin{tabular}{|c|c|c|c|c|c|c|c|c|}
\hline & $\mathrm{Wu}$ & & & & & & & $\begin{array}{l}\text { environment, and de- } \\
\text { velop ear recognition } \\
\text { capability at a distance, } \\
\text { in the outdoor environ- } \\
\text { ment }\end{array}$ \\
\hline 18 & $\begin{array}{l}\text { Juan Ma- } \\
\text { nuel Pas- } \\
\text { cual- } \\
\text { Gaspar, } \\
\text { Marcos } \\
\text { Faundez- } \\
\text { Zanuy, } \\
\text { Carlos } \\
\text { Vivaracho } \\
2011\end{array}$ & Signature & 330 & $\begin{array}{l}\text { MCYT, } \\
\text { SVC }\end{array}$ & $\begin{array}{l}\text { vector quantization } \\
\text { algorithm }\end{array}$ & NA & $\begin{array}{l}99 . \\
76\end{array}$ & $\begin{array}{l}\text { improvement in speed } \\
\text { when compared with } \\
\text { the state-of-the-art al- } \\
\text { gorithms }\end{array}$ \\
\hline 19 & $\begin{array}{l}\text { Yasmine } \\
\text { Serdouk, } \\
\text { Hassiba } \\
\text { Nemmour, } \\
\text { Youcef } \\
\text { Chibani } \\
2016\end{array}$ & Signature & 155 & $\begin{array}{l}\text { CEDAR } \\
\text { and } \\
\text { GPDS- } \\
100\end{array}$ & $\begin{array}{l}\text { Artificial Immune } \\
\text { Recognition Sys- } \\
\text { tem }\end{array}$ & NA & NA & $\begin{array}{l}\text { Develop a train able } \\
\text { decision function. }\end{array}$ \\
\hline 20 & $\begin{array}{lr}\text { K S } & \text { Rad- } \\
\text { hika, } & \text { Go- } \\
\text { pika } & \text { S } \\
2014 & \end{array}$ & $\begin{array}{l}\text { Online \& } \\
\text { Offline } \\
\text { Signature }\end{array}$ & 55 & NA & $\begin{array}{l}\text { Gradient feature, } \\
\text { SVM }\end{array}$ & SVM & $\begin{array}{l}76 . \\
92\end{array}$ & NA \\
\hline 21 & $\begin{array}{l}\text { Radhey } \\
\text { Shyam, } \\
\text { Yogendra } \\
\text { Narain } \\
\text { Singh } \\
2015\end{array}$ & Face & NA & $\begin{array}{l}\text { AT \& T- } \\
\text { ORL }\end{array}$ & $\begin{array}{l}\text { local binary pat- } \\
\text { tern(LBP), Aug- } \\
\text { mented Local Bi- } \\
\text { nary } \quad \text { Pattern } \\
\text { (ALBP) }\end{array}$ & NA & NA & NA \\
\hline 22 & $\begin{array}{l}\text { Ping Yan, } \\
\text { Kevin W. } \\
\text { Bowyer }\end{array}$ & Ear & 404 & NA & ICP & NA & $\begin{array}{c}97 . \\
5\end{array}$ & NA \\
\hline 23 & $\begin{array}{l}\text { Snehlata } \\
\text { Barde, A. } \\
\text { S. Zad- } \\
\text { gaonkar, } \\
\text { G. R. } \\
\text { Sinha } \\
2014\end{array}$ & $\begin{array}{l}\text { Face, Ear } \\
\text { and Iris }\end{array}$ & 100 & NA & $\begin{array}{l}\text { PCA, NN classifer, } \\
\text { Euclidian distance, } \\
\text { Hamming distance. }\end{array}$ & $\begin{array}{l}\text { score } \\
\text { level }\end{array}$ & 99 & $\begin{array}{l}\text { Improved performance } \\
\text { in terms of recognition } \\
\text { accuracy, FAR and } \\
\text { FRR }\end{array}$ \\
\hline 24 & $\begin{array}{l}\text { Md. Ma- } \\
\text { ruf Mon- } \\
\text { war and } \\
\text { Marina } \\
\text { Gavrilova } \\
2008\end{array}$ & $\begin{array}{l}\text { Face, Ear } \\
\& \text { Signa- } \\
\text { ture }\end{array}$ & $\begin{array}{l}\text { Face- } \\
102\end{array}$ & $\begin{array}{l}\text { ORL } \\
\text { Universi- } \\
\text { ty of } \\
\text { Rajshahi } \\
\text { signature } \\
\text { database }\end{array}$ & PCA, FLD & $\begin{array}{l}\text { Rank } \\
\text { Level }\end{array}$ & NA & NA \\
\hline 25 & $\begin{array}{l}\text { U. M. } \\
\text { Bubeck el } \\
\text { at. }\end{array}$ & $\begin{array}{l}\text { Face, Ear } \\
\text { and Iris }\end{array}$ & $\begin{array}{l}\text { Indi- } \\
\text { vidual }\end{array}$ & NA & PCA & $\begin{array}{l}\text { PCA } \\
\text { based } \\
\text { neur- } \\
\text { al } \\
\text { net- } \\
\text { work }\end{array}$ & NA & NA \\
\hline
\end{tabular}

\section{PROPOSED METHODOLOGY}

Rank level fusion is the technique of consolidate other than two identification results to enhance the reliability in character identification. In multimodal biometric system (MBS), rank level fusion can be used to combine the biometrics match scores starting the dissimilar biometric modalities (for example face, fin- gerprint, palmprint, and iris). Borda count method and Logistic regression method are the main approaches for this fusion scheme. Borda count method uses the sum of the ranks assigning by individual matchers to calculate the consensus rank and Logistic regression method, a weighted sum of the individual ranks is calculated. 
In that paper (PCA) Principal Component Analysis and FLD Fisher's Linear Discriminant (FLD) methods in FES. Although PCA based multimodal biometric system have been developed by some researchers, but very limited research has been done utilizing FLD for multibiometrics systems. Also rank fusion is investigated very few times but with PCA and FLD, this method has not been studied yet. Moreover, both methods can output the rank of individuals very precisely. So, for achieving higher recognition rate, rank level fusion for FES to consolidate the results produced by monomodal matchers. The block diagram of FES is shown in figure1 [25].

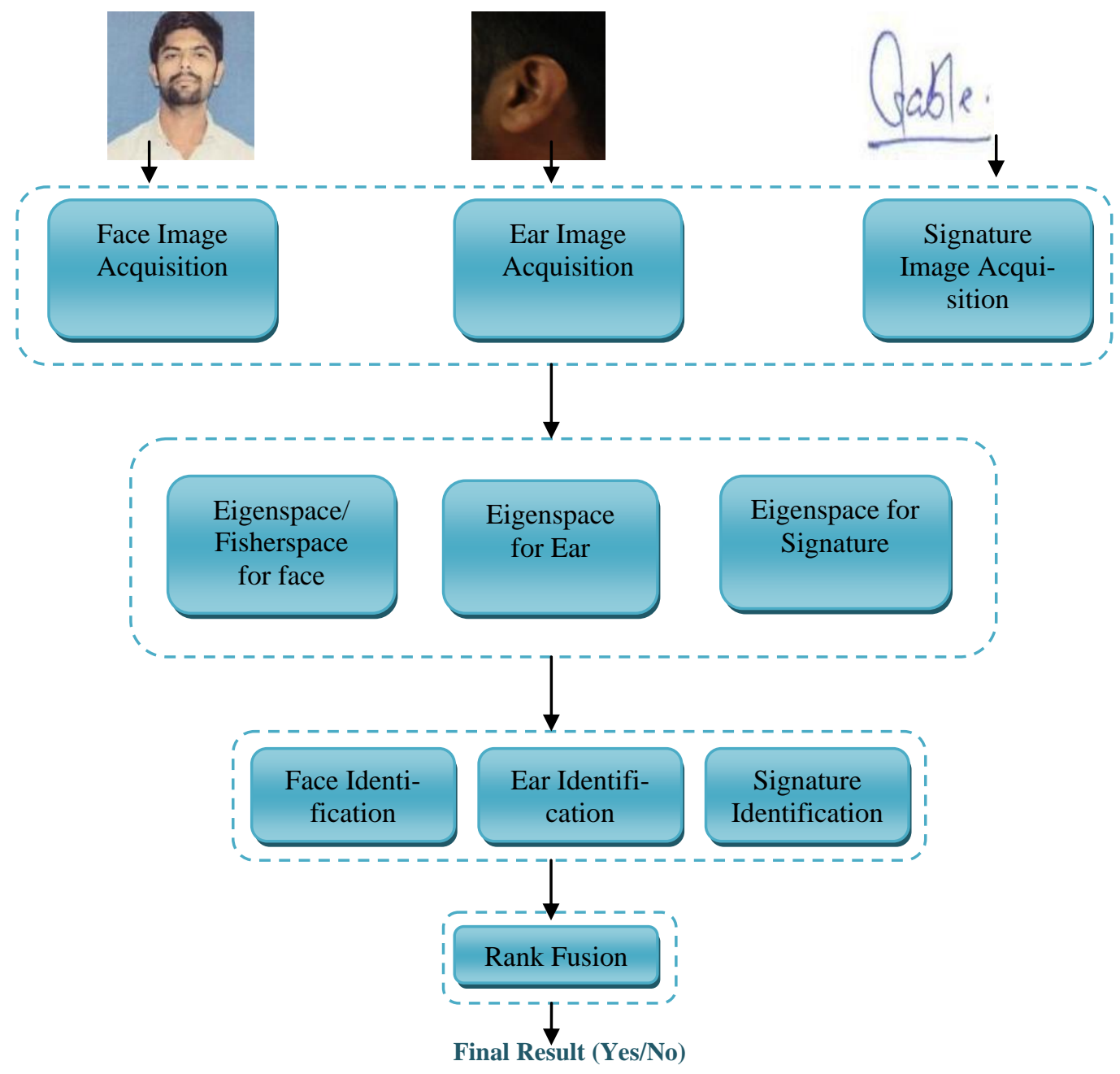

Fig. : Flowchart of the Proposed Solution

Local features are extracted from face, ear and signature data. A number of distinctive feature point locations (key points) are selected on the face, ear and signature region based on the asymmetrical variations in depth around them. Features are match using Euclidean distance and rotation angles between the underlying coordinate bases of the features are computed as described.

\section{CONCLUSION}

From the review conducted on face, ear and signature multimodal biometric techniques, the development of that multimodal system with a PCA and FLD based multimodal biometric system and integrating face, ear and signature through rank level fusion approach, Three unimodal systems will be developing for identification. PCA and FLD method give better recognition performance than eigenimage technique. With help of that review paper we can develop multimodal biometric system for face, ear and signature using rank level fusion with better recognition rate.

\section{REFERENCES}

[1] R. Raghavendra "Novel mixture model-based approaches for person verification using multimodal biometrics" Springer-Verlag London Limited 2012, pp.1015-1028

[2] Cheng Lu, Jisong Wang, Miao Qi "Multimodal Biometric Identification Approach Based on Face and Palmprint" Second International Symposium on Electronic Commerce and Security IEEE 2009, pp.44-47

[3] Sheetal Chaudhary, Rajender Nath "A Multimodal Biometric Recognition System Based on Fusion of Palmprint, Fingerprint and Face" International Conference on Advances in Recent Technologies in Communication and Computing 2009 pp.596-600

[4] Kyong I. Chang, Kevin W. Bowyer, and Patrick J. Flynn "An Evaluation of Multimodal 2D+3D Face Biometrics, “ IEEE Transactions On Pattern Analysis And Machine Intelligence, April 2005 , Vol. 27, No. 4, pp.619-924 
[5] Teddy Ko "Multimodal Biometric Identification for Large User Population Using Fingerprint, Face and Iris Recognition, " Proceedings of the 34th Applied Imagery and Pattern Recognition Workshop (AIPR05) IEEE 2005

[6] Muhammad Imran Ahmad, Wai Lok Woo, Satnam Dlay, "Non-stationary feature fusion of face and palmprint multimodal biometrics", Elsevier Neurocomputing 177 (2016) pp. 49-61

[7] S.M. Mahbubur Rahman, Tamanna Howlader, Dimitrios Hatzinakos ,"On the selection of 2D Krawtchouk moments for face recognition”, Elsevier Pattern Recognition 2016 pp.1-11

[8] M.Pujitha Raj, Manjusha.R, B.Achyut Sarma, S.Vaishnavi, "Multi-modal Biometric system using ear and face $(2 \mathrm{D}+3 \mathrm{D})$ Modalities", International Journal of Computer Science \& Communication Networks ,Vol 5(2), pp.67-71

[9] Xiaona Xu, Zhichun Mu, "Multimodal Recognition Based on Fusion of Ear and Profile Face" Fourth International Conference on Image and Graphics IEEE 2007, pp.598603

[10] Javier Ortega-Garcia, Julian Fierrez, Fernando AlonsoFernandez, Javier Galbally, Manuel R. Freire, GonzalezRodriguez, Carmen Garcia-Mateo, Jose-Luis Alba-Castro, Elisardo Gonzalez-Agulla, Enrique Otero-Muras, Sonia Garcia-Salicetti, Lorene Allano, Bao Ly-Van, Bernadette Dorizzi, Josef Kittler, Thirimachos Bourlai, Norman Poh, Farzin Deravi, Ming W.R. Ng, Michael Fairhurst, Jean Hennebert, Andreas Humm, Massimo Tistarelli, Linda Brodo, Jonas Richiardi, Andrzej Drygajlo, Harald Ganster, Federico M. Sukno, Sri-Kaushik Pavani, Alejandro Frangi, Lale Akarun, Arman Savran, "The Multiscenario Multienvironment BioSecure Multimodal Database (BMDB)", IEEE Transactions On Pattern Analysis And Machine Intelligence, Vol. 32, No. 6, June 2010, Pp.1097-1111

[11] Lin Hong and Anil Jain," Integrating Faces and Fingerprints for Personal Identification", IEEE Transactions On Pattern Analysis And Machine Intelligence, Vol. 20, No. 12, December 1998, pp. 1295- 1307

[12] Li Yuan, Wei Liu, Yang Li," Non-negative dictionary based sparse representation classification for ear recognition with occlusion", Neurocomputing Elsevier 2015, pp. $540-550$

[13] Asmaa Sabet Anwar, Kareem Kamal A.Ghany, Hesham Elmahdy," Human Ear Recognition Using Geometrical Features Extraction", Elsevier International Conference on Communication, Management and Information Technology (ICCMIT 2015), pp. $529-537$

[14] Francis F. Li," Sound-Based Multimodal Person Identification from Signature and Voice", The Fifth International Conference on Internet Monitoring and Protection IEEE
2010, pp.84-88

[15] JuCheng Yang," Biometrics Verification Techniques Combing with Digital Signature for Multimodal Biometrics Payment System", International Conference on Management of e-Commerce and e-Government IEEE 2010, pp. $405-410$

[16] Arn Ross, Anil Jain," Information fusion in biometrics", Pattern Recognition Letters 24 Elsevier 2003, pp.21152125

[17] Ajay Kumar, Chenye Wu" Automated human identification using ear imaging", Pattern Recognition in Elsevier 2012, pp. 956-968

[18] Juan Manuel Pascual-Gaspar, Marcos Faundez-Zanuy, Carlos Vivaracho," Fast on-line signature recognition based on VQ with time modeling", Engineering Applications of Artificial Intelligence Elsevier 2011, pp. 368-377

[19] Yasmine Serdouk, Hassiba Nemmour, Youcef Chibani," New offline Handwritten Signature Verification method based on Artificial Immune Recognition System”, Expert Systems With Applications 51 Elsevier (2016) , pp.186194

[20] K S Radhika, Gopika S" Online and Offline Signature Verification: A Combined Approach", International Conference on Information and Communication Technologies Elsevier (ICICT 2014), pp. 1593 - 1600

[21] Radhey Shyam, Yogendra Narain Singh, "Identifying Individuals using Multimodal Face Recognition Techniques", International Conference on Intelligent Computing, Communication \& Convergence Elsevier (ICCC2014), pp. $666-672$

[22] Ping Yan, Kevin W. Bowyer, "Empirical Evaluation of Ear Biometrics"

[23] Snehlata Barde, A. S. Zadgaonkar, G. R. Sinha, "Multimodal Biometrics using Face, Ear and Iris Modalities", International Journal of Computer Applications2014, pp.0915

[24] Md. Maruf Monwar and Marina Gavrilova, "FES: A System for Combining Face, Ear and Signature Biometrics using Rank Level Fusion", IEEE Fifth International Conference on Information Technology: New Generations 2008 PP 922-927

[25] U. M. Bubeck, and D. Sanchez, "Biometric authentication: Technology \& evaluation", Tech. Report, San Diego State University, USA, 2003.

[26] Sumegh Tharewal,Hanumant Gite,K V Kale,"3D Face and 3D Ear Recognition: Process and Techniques", (ICCTCEEC) 8 \& 9 SEP 2017 Vidyavardhka College of Ebgineering, Mysuru, Karnataka, India. 